\title{
Viviparus ater Hemocyanin: Investigation of the Dioxygen-Binding Site and Stability of the Oxy- and Apo-Forms
}

\author{
Dessislava Nikolova Georgieva ${ }^{\mathrm{a}}$, Stanka Stoeva ${ }^{\mathrm{b}}$, Wolfgang Voelter ${ }^{\mathrm{b}}$ and Nicolay \\ Genov ${ }^{\mathrm{a} *}$ \\ a Institute of Organic Chemistry, Bulgarian Academy of Sciences, Acad. G. Bonchev-Str. \\ bl. 9, Sofia 1113, Bulgaria. Fax: 00359-2-700 225. E-mail: genov-n@yahoo.com \\ b Abteilung für Physikalische Biochemie, Physiologisch-chemisches Institut der Universität \\ Tübingen, Hoppe-Seyler-Straße 4, D-72076 Tübingen, Germany
}

*Author for correspondence and reprint requests

Z. Naturforsch. 56c, 843-847 (2001); received April 9/May 18, 2001

Dioxygen Transport, Hemocyanin, Mollusc

The active site of Viviparus ater (mollusc) hemocyanin was investigated using the fact that the binding of dioxygen to the binuclear copper-containing sites of hemocyanins is connected with the appearance of specific dichroic bands which are very sensitive to changes in the structrure and polarity of the environment. Oxy-Viviparus ater hemocyanin exhibits near UV and visible circular dichroism spectra different from those of other molluscan and arthropodan hemocyanins. These differences are due probably to variations in the geometry or charge distribution in the dioxygen binding sites of the compared proteins.

The thermostability of Viviparus ater hemocyanin and the significance of the copper-dioxygen system for the stability were also investigated. "Melting " temperatures, $T_{\mathrm{m}}$, of $77{ }^{\circ} \mathrm{C}$ for the oxy-hemocyanin and $57^{\circ} \mathrm{C}$ for the apo-protein were calculated from the denaturation curves which demonstrates the considerable role of the binuclear active site for the thermostability. Viviparus ater hemocyanin is more thermostable than other hemocyanins for which data are published.

\section{Introduction}

Hemocyanins (Hcs) are copper-containing dioxygen-transporting proteins freely dissolved in the hemolymph of mollusca and arthropoda. These giant biopolymers are the most complex and sophisticated respiratory proteins, comparable in size to ribosomes or small viruses (Sterner and Decker, 1994). Hcs bind dioxygen reversibly at a binuclear active site and ensure its circulatory transport to the tissues. In the hemolymph, Hcs exist as aggregates of subunits (polypeptide chains). Although similar in function, arthropodan and molluscan respiratory proteins differ in the organization and size of the subunits. Arthropodan Hcs are composed of six or multiples of six subunits with a molecular mass of the individual polypeptide chain in the region of $67-90 \mathrm{kDa}$ (Herskovits, 1988). Each structural/functional subunit contains a single binuclear copper-containing dioxygenbinding site. Molluscan Hcs form cylindrical mono- (cephalopods) or didecameric (gastropods) structures. The wall of the decamer is made up of
60 globular functional units (FUs) and an internal „collar" containing 10 or 20 functional units (Lieb et al., 2000). The subunits are composed of 7 (cephalopods) or 8 (some cephalopods and gastropods) $50 \mathrm{kDa}$ FUs. Each FU contains a single active site (van Holde et al., 1992). During the last decade some Hcs were used for medical purposes. Thus, the Hc from the gastropod Megathura crenulata is widely used in laboratories and clinics as an immune stimulant (Jennemann et al., 1994), in the immunotherapy of cancer (Lamm et al., 1993) as well as for the preparation of vaccines (Wang et al., 2000).

The complete amino acid sequences of two molluscan Hc structural subunits, those from the cephalopod Octopus dofleini (Miller et al., 1998) and gastropod Haliotis tuberculata (Lieb et al., 2000), as well as the complete molecular structure of the arthropod Hc from Euripelma californicum (Voit et al., 2000) have been determined. The first crystallographic structure of a FU from molluscan Hc has recently been reported (Cuff et al., 1998). The structure of a molluscan $\mathrm{Hc}$ didecamer, HtH1 
from the H. tuberculata, has been solved at $1.2 \mathrm{~nm}$ resolution by cryoelectron microscopy (Meissner et al., 2000).

The copper-dioxygen system at the $\mathrm{Hc}$ active site generates CD spectra in the visible region and near ultraviolet (Ellerton et al., 1983). In this paper we describe studies performed with the aim of characterizing the binuclear active site of the Viviparus ater (gastropod, mollusc) Hc and its significance for the protein thermostability.

\section{Materials and Methods}

\section{Materials}

Viviparus ater hemocyanin was a generous gift from Professor B. Salvato (University of Padova, Italy). The protein in oxy-form was purified by the method described in (Ricchelli et al., 1984). Apo$\mathrm{Hc}$ (hemocyanin in which the copper-dioxygen system is removed) was obtained by dialysis against $25 \mathrm{~mm} \mathrm{KCN} \mathrm{(Salvato} \mathrm{et} \mathrm{al.,} \mathrm{1974).} \mathrm{All}$ chemicals and reagents were of analytical grade.

\section{Amino acid analysis}

The copper ions were completely removed from the protein samples by precipitation of the apoprotein with trichloroacetic acid and washing the pellet with several portions of $0.1 \mathrm{M} \mathrm{HCl}$. Amino acid composition of the Viviparus ater $\mathrm{Hc}$ was determined after hydrolysis in $5.7 \mathrm{M} \mathrm{HCl}$ in evacuated sealed tubes for 24,48 and $72 \mathrm{~h}$ at $110^{\circ} \mathrm{C}$. For tryptophan determination the samples were hydrolyzed in the presence of $5 \%$ thioglycolic acid. An Eppendorf model LC 3000 automatic amino acid analyzer was used. The values are expressed as number of amino acid residues per functional unit of $50 \mathrm{kDa}$.

\section{Spectroscopic measurements}

Circular dichroism spectra were recorded and the thermal denaturation of the oxy- and apo-Hc followed using a Jasco J-720 dichrograph, equipped with a personal computer IBM PC-AT, PS/ 2, multiscan monitor CMS-3436 and a HewlettPackard colour graphics plotter model HP 7475 A. A DOS software was used for calculations with the CD data. Protein solutions in $50 \mathrm{~mm}$ Tris-(hydroxymethyl)-aminomethan hydrochloride buffer, $\mathrm{pH} 7.0$, containing $5 \mathrm{~mm} \mathrm{CaCl}_{2}$, were placed in a cell holder which was thermostatically controlled using a NESLAB thermostat model RTE-110, connected with a digital programming controller. The samples were kept for $10 \mathrm{~min}$ at the desired temperature to ensure the attainment of thermal equilibrium, which was confirmed by the constancy of the ellipticity. Each spectrum presented is an average of three measurements. The $\mathrm{CD}$ data are expressed in terms of $[\theta]$, i. e. the mean residue molar ellipticity. The protein concentration was determined using $\varepsilon_{280}=7.14 \times 10^{4} \mathrm{M}^{-1} \mathrm{~cm}^{-1}$ per functional unit.

\section{Results and Discussion}

Table I shows the amino acid composition of Viviparus ater Hc. A relatively high content of acidic amino acids, Asp and Glu, was observed. The amount of these amino acids is $21 \%$ of the total content. Comparison with the compositions of other molluscan Hcs (Ghiretti-Magaldi et al., 1966) shows similarities.

Far UV CD spectra of oxy-Viviparus ater $\mathrm{Hc}$ at different temperatures are shown in Fig. 1. The spectra are dominated by negative bands at $220-$ $222 \mathrm{~nm}$ and a shoulder at $210 \mathrm{~nm}$, connected mainly with the $\alpha$-helix structure. Similar spectra

Table I. Amino acid composition of Viviparus ater hemocyanin. The samples are hydrolyzed in $5.7 \mathrm{~N} \mathrm{HCl}$ or in $5 \%$ thioglycolic acid for 24,48 and $72 \mathrm{~h}$ at $110^{\circ} \mathrm{C}$. The values are expressed as number of amino acid residues per functional unit of $50 \mathrm{kDa}$.

\begin{tabular}{lc}
\hline Amino acid & Viviparus ater hemocyanin \\
\hline Aspartic acid & 47 \\
Threonine & 22 \\
Serine & 27 \\
Glutamic acid & 44 \\
Proline & 26 \\
Glycine & 29 \\
Alanine & 30 \\
Half cystine & 6 \\
Valine & 23 \\
Methionine & 8 \\
Isoleucine & 16 \\
Leucine & 35 \\
Tyrosine & 20 \\
Phenylalanine & 28 \\
Histidine & 29 \\
Lysine & 19 \\
Arginine & 21 \\
Tryptophan & 8 \\
Total & 438 \\
\hline
\end{tabular}




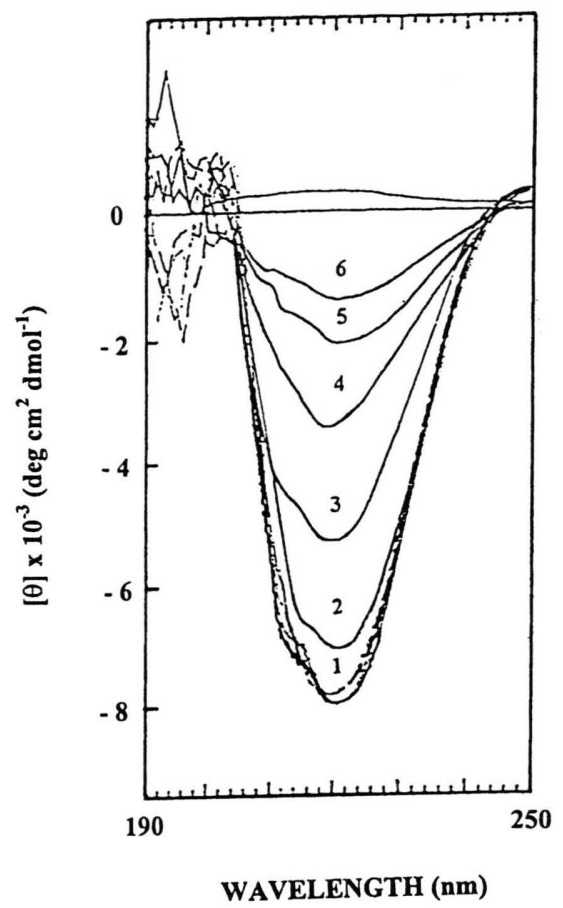

Fig. 1 Characteristic circular dichroism spectra in the far ultraviolet region of oxy-Viviparus ater hemocyanin at $\mathrm{pH}$ 7.0. The spectra are recorded at the following temperatures: (1), $15-40^{\circ} \mathrm{C} ;(2), 65^{\circ} \mathrm{C} ;(3), 75^{\circ} \mathrm{C}$; (4), $78^{\circ} \mathrm{C} ;(5), 81^{\circ} \mathrm{C}$ and $(6), 84^{\circ} \mathrm{C}$.

in the peptide region below $250 \mathrm{~nm}$, were observed for other Hcs.

Two main transitions in the CD spectrum of the oxy-Hc were observed between 250 and $300 \mathrm{~nm}$ with bands at 254 and $294 \mathrm{~nm}$ and small shoulders at 275 and $287 \mathrm{~nm}$ (Fig. 2). The spectrum in the near UV region is due to contributions of aromatic residues. The $254 \mathrm{~nm}$ band may be due to tyrosine transitions (Tamburro et al., 1976). The presence of this band in the spectrum of apo-Hc suggests that the transition does not arise from a chromophore associated with the active site. The band at $294 \mathrm{~nm}$ is mainly from contributions of tryptophyl residues.

The $300-800 \mathrm{~nm}$ region in the spectrum of oxy$V$. ater $\mathrm{Hc}$ is characterized by 4 main transitions. The bands in this region are characteristic of the active site copper-dioxygen system and disappear on destruction of the active site (Figs. 2 and 3). This is demonstrated by the CD spectra of the apo-Hc shown in the same figures. The CD spectrum in the $250-500 \mathrm{~nm}$ range, reported in

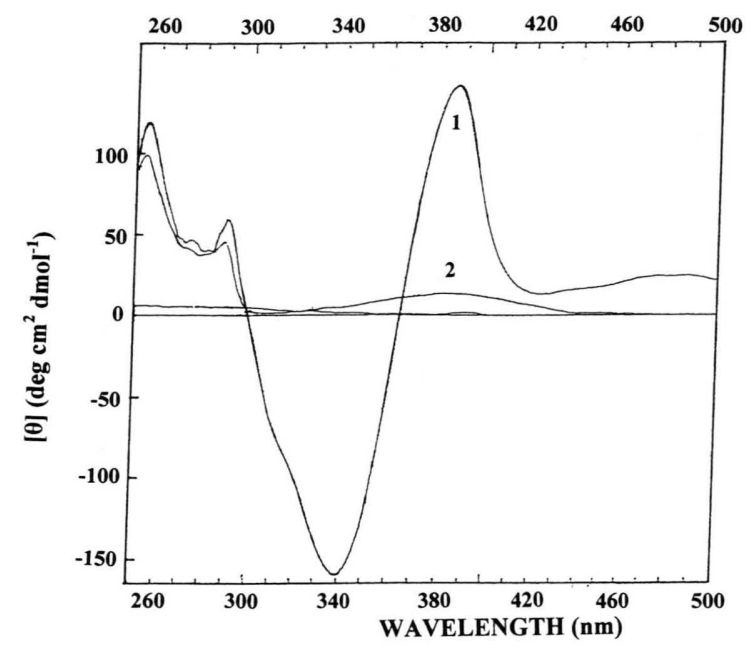

Fig. 2 250-500 nm circular dichroism spectra of oxy-(1) and apo-(2) Viviparus ater hemocyanin at $\mathrm{pH}$ 7.0.

Fig. 2, is dominated by a strong negative band at $340 \mathrm{~nm}$ and a positive band at $387 \mathrm{~nm}$. The negative $340 \mathrm{~nm}$ band is common for the Hcs of both phyla, Arthropoda and Mollusca, and has been assigned to the peroxide $\pi \sigma^{*} \rightarrow \mathrm{Cu}(\mathrm{II}) \mathrm{d}\left(x^{2}-y^{2}\right)$ charge transfer transition (Beltramini et al., 1992). The CD bands in the spectra of Hcs above $300 \mathrm{~nm}$ should be attributed to the bicupric-peroxo system at the active site (Ellerton et al., 1983).

Oxy-Viviparus ater Hc exhibits near UV and visible CD spectra (Figs. 2 and 3), different from those of other molluscan and arthropodan oxyHcs. Thus, the strong positive band at $387 \mathrm{~nm}$ is absent in the CD spectra of the other Hcs, reported so far (Tamburro et al., 1976; Ellerton et al., 1983; Salvato and Beltramini, 1990; Boteva et al., 1991; Beltramini et al., 1992) Arthropod oxyHcs have negative bands at 260-300 and $340 \mathrm{~nm}$ and positive bands at 490 and $610 \mathrm{~nm}$. Molluscan oxy-Hcs exhibit negative bands at 340 and $570 \mathrm{~nm}$ and positive bands in the region of $260-300 \mathrm{~nm}$, at 450 and $710 \mathrm{~nm}$ (Ellerton et al., 1983).

In the visible $\mathrm{CD}$ spectrum of oxy- $V$. ater $\mathrm{Hc}$ a small positive dichroism is observed in the 450$520 \mathrm{~nm}$ region (Fig. 3). Also, negative dichroism is observed between 520 and $720 \mathrm{~nm}$ with a shoulder at $610 \mathrm{~nm}$ and a strong negative peak at $658 \mathrm{~nm}$ (Fig. 3). The CD spectra of other molluscan Hcs in this spectral region, reported in the literature so far, do not exhibit a strong negative band at 


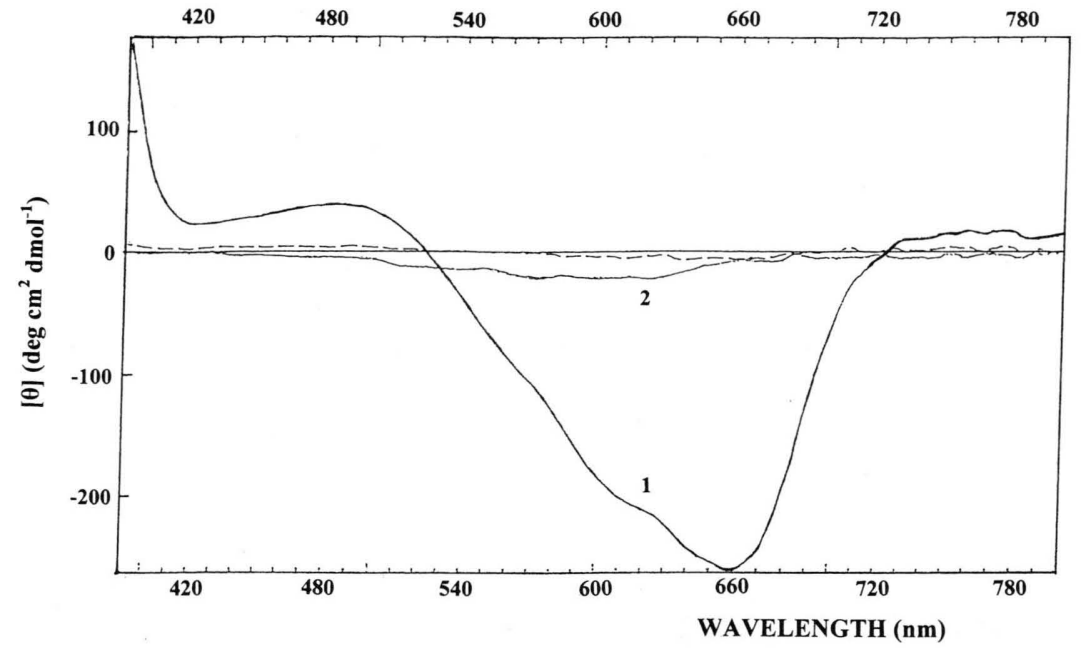

Fig. 3 Circular dichroism spectra of oxy-(1) and apo-(2) Viviparus ater hemocyanin in the visible spectral range at $\mathrm{pH}$ 7.0.
$658 \mathrm{~nm}$; they have a positive maximum around $700 \mathrm{~nm}$ and negative bands at $570-580 \mathrm{~nm}$ (Tamburro et al., 1976; Ellerton et al., 1983; Boteva et al., 1991). The differences between the CD spectrum above $365 \mathrm{~nm}$ of oxy- $V$. ater $\mathrm{Hc}$ and the respective spectra, reported for molluscan and arthropodan $\mathrm{Hcs}$, are due probably to geometric variations in the dioxygen binding sites. The bands in this spectral region are absent in the CD spectra of apo-V. ater $\mathrm{Hc}$ with a destroyed active site (Figs. 2 and 3). Differences in position and surrounding of side chains near to this site and any changes in the charge distribution at the active site can create changes in optical activity caused by the copperdioxygen system.

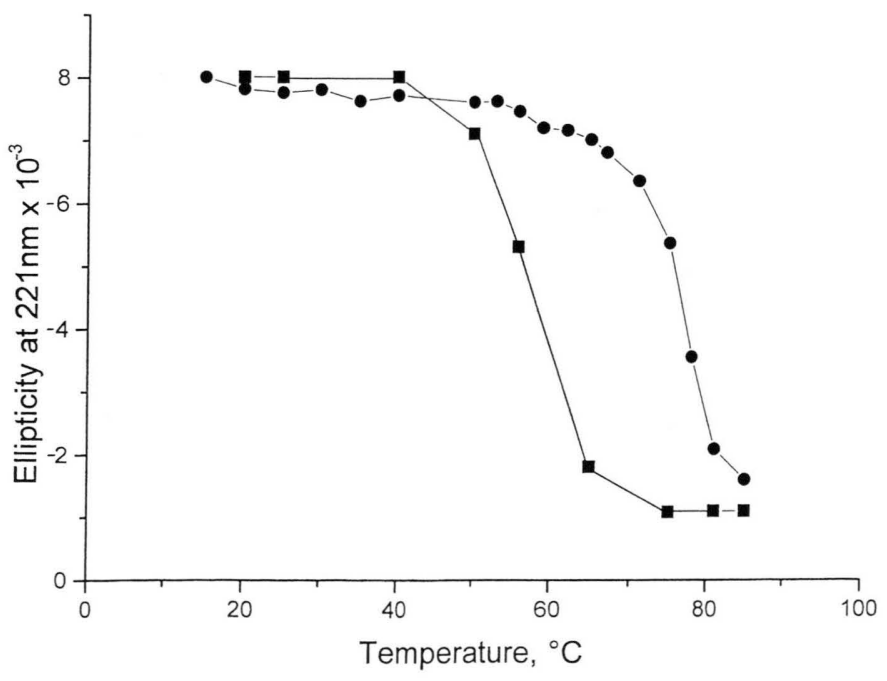

In order to investigate the thermostability of $V$. ater $\mathrm{Hc}$ and the significance of the copper-dioxygen system at the active site for the stability, we followed changes in the ellipticity of hemocyanin samples at temperatures up to $85^{\circ} \mathrm{C}$ (Fig. 1). A decrease of the negative ellipticity was observed at temperatures higher than $60^{\circ} \mathrm{C}$ for the oxy-Hc and $40^{\circ} \mathrm{C}$ for the apo-Hc. Single wavelength melting curves (SWMCs), measured by $\mathrm{CD}$, are shown in Fig. 4. We have followed only the forward reaction because the thermal denaturation of both, oxy- and apo-form, was irreversible. The irreversibility of the Hc denaturation is probably connected with an aggregation of the giant biomolecules (Guzman-Casado et al., 1990). "Melting"
Fig. 4 Single wavelength melting curves, measured by circular dichroism, for the thermal denaturation of oxy- $(\bullet-\bullet)$ and apo- $(--\bullet)$ Viviparus ater hemocyanin at $\mathrm{pH} 7.0 \mathrm{~T}_{\mathrm{m}}$ values of 77 and $57{ }^{\circ} \mathrm{C}$ were calculated for the oxy- and apo-form, respectively. The data are expressed in terms of mean residue molar ellipticity. 
temperatures, $T_{\mathrm{m}}$, of $77^{\circ} \mathrm{C}$ for the oxy-Hc and $57^{\circ} \mathrm{C}$ for the apo-protein were calculated from the midpoints of SWMCs (Fig. 4). This result demonstrates the considerable role of the binuclear active site for the thermostability of hemocyanin molecule. The removal of the copper-dioxygen system from the active site led to a decrease of the "melting" temperature by $20^{\circ} \mathrm{C}$. Comparison with the thermostability of other molluscan Hcs, for

Beltramini M., Bubacco L., Salvato B., Casella L., Gullotti M. and Garofani S. (1992), The aromatic circular dichroism spectrum as a probe for conformational changes in the active site environment of hemocyanins. Biochim. Biophys. Acta 1120, 24-32.

Boteva R., Severov S., Genov N., Beltramini M., Filippi B., Ricchelli F., Tallandini L., Pallhuber M. M., Tognon G. and Salvato B. (1991), Biochemical and functional characterization of Rapana thomasiana hemocyanin. Comp. Biochem. Physiol. 100B, 493-501.

Cuff M. E., Miller K. I., van Holde K. E. and Hendrickson W. A. (1998), Crystal structure of a functional unit from Octopus hemocyanin. J. Mol. Biol. 278, 855-870.

Ellerton H. D., Ellerton N.F. and Robinson H. A. (1983), Hemocyanin - a current perspective. Prog. Biophys. Mol. Biol. 41, 143-248.

Georgieva D. N., Stoeva S., Ali S. A., Abbasi A., Genov N. and Voelter W. (1998), Circular dichroism study of the hemocyanin thermostability. Spectrochim. Acta A54, 765-771.

Ghiretti-Magaldi A., Nuzzolo C. and Ghiretti F. (1966), Chemical studies on hemocyanins. I. Amino acid composition. Biochemistry 5,1943-1951.

Guzman-Casado M., Parody-Morreale A., Mateo P. L. and Sanchez-Ruiz J. M. (1990), Differential scanning calorimetry of lobster haemocyanin. Eur. J. Biochem. 188, $181-185$.

Herskovits T. T. (1988), Recent aspects of the subunit organization and dissociation of hemocyanins. Comp. Biochem. Physiol. 91B, 597-611.

Jennemann R., Gnewuch C., Bosslet S., Bauer B. L. and Wiegandt H. (1994), Specific immunization using keyhole limpet hemocyanin-ganglioside conjugates. J. Biochem. (Tokyo) 115, 1047-1052.

Lamm D. L., DeHaven J. I., Riggs D. R. and Ebert R. F. (1993), Keyhole limpet hemocyanin immunotherapy of murine bladder cancer. Urol. Res. 21, 33-37.

Lieb B., Altenhein B. and Markl J. (2000), The sequence of a gastropod hemocyanin (HtH1 from Haliotis tuberculata). J. Biol. Chem. 275, 5675-5681. which data are published (Georgieva et al., 1998), shows that the respiratory protein from Viviparus ater is more stable by $11-21^{\circ} \mathrm{C}$ in its melting point.

\section{Acknowledgement}

We express our gratitude to the Internationales Büro des BMBF, Bonn, Germany, for financial support by the research grant BUL-99-001.

Meissner U., Dube P., Harris J. R., Stark H. and Markl J. (2000), Structure of a molluscan hemocyanin didecamer (HtH1 from Haliotis tuberculata) at $12 \AA$ resolution by cryoelectron microscopy. J. Mol. Biol. 298, $21-34$.

Miller K. I., Cuff M. E., Lang W. F., Varga-Weisz P., Field K. G. and van Holde K. E. (1998), Sequence of the Octopus dofleini hemocyanin subunit: structural and evolutionary implications. J. Mol. Biol. 278, 827-842.

Ricchelli F., Jori G., Tallandini L., Zatta P., Beltramini M. and Salvato B. (1984), The role of copper and quaternary structure on the conformational properties of Octopus vulgaris hemocyanin. Arch. Biochem. Biophys. 235, $461-469$.

Salvato B., Ghiretti-Magaldi A. and Ghiretti F. (1974), Acid-base titration of hemocyanin from Octopus vulgaris. Biochemistry 13, 4778-4783.

Salvato B. and Beltramini M. (1990), Hemocyanins: molecular architecture, structure and reactivity of the binuclear copper active site. Life Chem. Rep. 8, 1-47.

Sterner R. and Decker H. (1994), Inversion of the Bohr effect upon oxygen binding to 24-meric tarantula hemocyanin. Proc. Natl. Acad. Sci. U. S. A. 91, 48354839.

Tamburro A. M., Salvato B. and Zatta P. (1976), A circular dichroism study of some hemocyanins. Comp. Biochem. Physiol. 55B, 347-356.

Van Holde K. E., Miller K. I. and Lang W. H. (1992), Molluscan hemocyanins: structure and function. Adv. Comp. Environ. Physiol. 13, 257-300.

Voit R., Feldmaier-Fuchs G., Schweikardt T., Decker H. and Burmester T. (2000), Complete sequence of the 24-mer hemocyanin of the tarantula Eurypelma californicum. J. Biol. Chem. 275, 39339-39344.

Wang Z.-G., Williams L. J., Zhang X.-F., Zatorski A., Kudryashov V., Ragupathi G., Spassova M., Bornmann W., Slovin S. F., Scher H. I., Livingston P. O., Lloyd K. O. and Danishefsky (2000), Proc. Natl Acad. Sci. U. S. A. 97, 2719-2724. 